\title{
Heat-deproteinated xenogeneic bone from slaughterhouse waste: Physico-chemical properties
}

\author{
R MURUGAN ${ }^{\dagger}$, K PANDURANGA RAO ${ }^{\dagger}$ and T S SAMPATH KUMAR* \\ Department of Metallurgical \& Materials Engineering and RSIC, Indian Institute of Technology, Chennai 600036 , \\ India \\ ${ }^{\dagger}$ Biomaterials Laboratory, Central Leather Research Institute, Chennai 600 020, India
}

MS received 7 June 2002; revised 12 May 2003

\begin{abstract}
Xenogeneic bone procured from the slaughterhouse waste was deproteinated by heat treatment method intended for use as a bone substitute. The effect of heat treatment was investigated by thermal analysis and by physico-chemical methods such as X-ray powder diffraction (XRD) and Fourier transformed infrared (FTIR) spectroscopy. The heat treatment temperatures for the bovine bone samples were predetermined by thermogravimetric (TG) analysis. The XRD results revealed that the process of heat treatment promoted the crystallinity of bone samples, particularly at 700 and $900^{\circ} \mathrm{C}$. There was no secondary phase transformation detected for heat-deproteinated bone except the presence of the hydroxyapatite (HA) phase, which indicated its phase purity even at a higher temperature. The FTIR spectra of raw bone and bone heated at $300^{\circ} \mathrm{C}$ indicated the presence of organic macromolecules whereas these disappeared in the samples heated at 500,700 and $900^{\circ} \mathrm{C}$, which suggested the removal of antigenic organic matters around $500^{\circ} \mathrm{C}$. The same results were also confirmed quantitatively by calculating the amount of collagen using hydroxyproline estimation. There was no significant change in the TG-thermogram of bone heated at 500,700 and $900{ }^{\circ} \mathrm{C}$, which indicated their thermal stability. These findings implied that the heat treated bone at $500^{\circ} \mathrm{C}$ had properties similar to carbonated $\mathrm{HA}$ with low crystallinity, while 700 and $900^{\circ} \mathrm{C}$ samples had the same with higher crystallinity. As low temperature treatment does not alter morphological and structural properties, we propose that the $500^{\circ} \mathrm{C}$ heat treated xenogeneic bone may act as an excellent osteogenic bone substitute.
\end{abstract}

Keywords. Xenogeneic bone; deproteination; heat treatment; hydroxyapatite; crystallinity; bone substitute.

\section{Introduction}

The need to repair bone for osseous defects resulting from trauma, tumour and bone diseases has been recognized for the past few decades. Although autogeneous bone is the best candidate (Arrigton et al 1996; Tancred et al 1998), its limited volume and requisite additional surgery indicate a need for an alternative. Allogeneic bone could overcome these limitations, but it bears the risk of infections and immune response (Stevension 1999). So another possibility is to use material such as xenogeneic bone, which is morphologically and structurally similar to human bone. As compared to other methods, it is easy to obtain and has lower cost with faster recovery time. However, the problem of antigenicity remains open if xenogeneic bone is used as such, clinically (Urist et al 1994). To alleviate this, various chemical treatments have been developed to remove the antigenic proteins and cellular elements of xenogeneic bone (Katthagen 1986). The results show that the chemically deproteinated materials retain some antigenicity, which could evoke immu-

\footnotetext{
*Author for correspondence
}

nological response. Recently, heat treatment has been suggested as an alternative to obtain protein-free xenogeneic bone (Lin et al 1999; Joschek et al 2000). The heattreated bone maintains the morphological structure of natural bone, which has an interconnective porous structure of $70 \%$ volume porosity and hence allows faster bone in-growth (Lin et al 1999).

The crystalline phase of heat treated xenogeneic bone resembles hydroxyapatite (HA) with composition, $\mathrm{Ca}_{10}\left(\mathrm{PO}_{4}\right)_{6}(\mathrm{OH})_{2}$. HA is a potential implant material as a bone substitute owing to its excellent biocompatible and osteoconductive properties (De Groot 1980; Jarcho 1981). Moreover using HA, as a bone substitute is advantageous, since it is non-inflammatory and causes no immunological, foreign body or irritating response (Paul and Sharma 1997). It is thermally stable up to $1200^{\circ} \mathrm{C}$, however, the decomposition temperature may vary depending upon the heating atmosphere (Locardi et al 1993). In addition, functional groups of HA are also an important factor for the decomposition temperature. Hence, the influence of heat treatment on the deproteination of xenogeneic bone at low and high temperatures is of great importance. Keeping the above points in view, the present study was aimed to prepare low cost heat- 
deproteinated xenogeneic bone obtained from the slaughterhouse waste for use as a potential bone substitute. The physico-chemical properties and the effect of temperature on deproteination were analysed systematically.

\section{Experimental}

\subsection{Materials}

An adult bovine tibia of $~ 5-6$ years old male was procured from local slaughterhouse. Sodium chloride and organic solvents used were of analytical grade (S.D. Fine Chem Ltd., India).

\subsection{Deproteination of xenogeneic bone}

The deproteination of xenogeneic bone was carried out by heat treatment process. In brief, the procured bone samples were cleaned well to remove macroscopic adhering impurities. These were dissected into smaller pieces and sliced longitudinally by cutting on a low speed saw (Buehler Ltd., USA) in running water. In order to avoid soot and crack formation during heat treatment, the bone samples were boiled in distilled water for $12 \mathrm{~h}$. After boiling, the bone samples were immersed in $2 \% \mathrm{NaCl}$ solution as a preservative for $12 \mathrm{~h}$ and degreased by immersing in acetone-ether mixture at a ratio of $3: 2$ for $24 \mathrm{~h}$ and then stored at $-20^{\circ} \mathrm{C}$ until assay (Raspanti et al 1994; Walsh et al 1994). The bone samples (5 g) were then pre-heated overnight at various temperatures i.e. $300,500,700$ and $900^{\circ} \mathrm{C}$. All the heat treatments were performed in a muffle furnace (Indfur, India) at $10^{\circ} \mathrm{C} /$ min in atmospheric pressure and ambient humidity. The amount of organic phase present in the bone samples was calculated by heating the bone samples at 300, 500, 700 and $900^{\circ} \mathrm{C}$ for $18 \mathrm{~h}$ and the weight changes of the sample were recorded at every $6 \mathrm{~h}$ for 3 times. The weight difference of the samples due to the variation of water content was adjusted with the average water content of all the samples used in this experiment. Finally all the samples were normalized to the bone heated at $700^{\circ} \mathrm{C}$ since it was reported that the heating at $700^{\circ} \mathrm{C}$ removed all the organic phases in $18 \mathrm{~h}$ (Gong et al 1964; Armstrong and Singer 1965).

\subsection{Physico-chemical characterization}

The thermogravimetric (TG) analysis of the bone samples during heat treatment was studied on $50 \mathrm{mg}$ of powder samples using Perkin-Elmer TG analyser (PE-7 series, USA). The measurements were recorded from 50 to $900^{\circ} \mathrm{C}$ at a heating rate of $10^{\circ} \mathrm{C} / \mathrm{min}$ in a stream of high purity nitrogen $(50 \mathrm{cc} / \mathrm{min})$. The amount of collagen present in the bone samples was calculated by indirect method using hydroxyproline estimation. For this, $100 \mathrm{mg}$ of raw bone and heat treated bone samples were hydrolyzed with $6 \mathrm{~N} \mathrm{HCl}$ in a sealed tube at $100^{\circ} \mathrm{C}$ for $18 \mathrm{~h}$. The insoluble residues were removed by filtration method. The hydrolyzed solution was then diluted with known volume of distilled water and analysed for hydroxyproline content (Neuman and Logan 1950). The phase purity and crystallographic parameters of the bone samples before and after heat treatment were examined with a high resolution X-ray powder diffractometer (XRD 3000, Seifert $\&$ Co, Germany) in a Guiner geometry using monochromatic $\mathrm{CuK} \alpha$ radiation at a wavelength of $1.5406 \AA$. The XRD patterns were recorded in steps of $0.01^{\circ}$ intervals with $1 \mathrm{~s}$ counting time at each step. The functional groups were identified by Fourier transform infrared spectroscopy (FTIR Nicolet 20 DxB spectrophotometer, Madison, USA) equipped with DTGS-KBr window detector using $\mathrm{KBr}$ pellets at a ratio of $1 \mathrm{mg}$ sample per $300 \mathrm{mg} \mathrm{KBr}$. The transmission IR spectra were recorded over the range of $400-4000 \mathrm{~cm}^{-1}$ with $2 \mathrm{~cm}^{-1}$ resolution averaging 100 scans. The carbonate content was determined, qualitatively, by spectroscopic method (Featherstone et al 1984) from the infrared spectrum of the bone sample by comparing the extinction coefficient $(E)$ of the $1450 \mathrm{~cm}^{-1}$ (carbonate) and $569 \mathrm{~cm}^{-1}$ (phosphate) peaks using the formula

$$
\% \mathrm{CO}_{3}=13 \cdot 5\left(E_{1450} / E_{569}\right)-0 \cdot 2
$$

where

$$
\left(E_{1450} / E_{569}\right)=E i=\log \left(T_{2}, I / T_{1}, I\right) .
$$

Here, " $i$ " is 1450 or $569 \mathrm{~cm}^{-1}$ and " $T_{2}, I$ " and " $T_{1}, I$ " are the transmission intensities at the peak maximum and local baseline, respectively. The carbonate content present in the prepared samples was also determined, quantitatively, as carbon using a carbon hydrogen nitrogen $(\mathrm{CHN})$ analyser (Medac, UK). Morphological structure of raw bone and heat-treated bone samples was studied by scanning electron microscope (SEM) (JEOL, Model-840A, Japan). The samples for SEM analysis were prepared by placing the raw bone and heated bone $\left(500^{\circ} \mathrm{C}\right)$ onto one side of a double adhesive tape, which was stuck to an aluminum stub. The stub was then coated with gold using a sputter coater (Polaron SC-500, UK) to a thickness of 20-30 nm and examined with an accelerating voltage of $15 \mathrm{kV}$.

\section{Results and discussion}

Bone is composed of about $70 \mathrm{wt} . \%$ inorganic and $30 \mathrm{wt} . \%$ organic components and it is necessary to remove the unwanted organic phases for use as a bone repair and regenerative material. In the present study, all the organic impurities were eliminated by heat treatment method in order to obtain antigenic-free inorganic bone minerals. To gain information about the thermal stability of xeno- 
geneic bone during heat treatment, the TG analysis of a small amount of raw bone was carried out and the thermogram is shown in figure 1. The thermogram of the raw bone shows initial weight loss up to $180^{\circ} \mathrm{C}$ pertaining to dehydroxylation. A continuous weight loss was observed from 300 to $480^{\circ} \mathrm{C}$ due to the decomposition of organic debris associated with the bone. There was no significant weight loss occurring between 500 and $900^{\circ} \mathrm{C}$, which may suggest that the proteins associated with the organic phase of xenogeneic bone were removed at the temperature $500^{\circ} \mathrm{C}$ and above. However, a small weight loss occurred at $720^{\circ} \mathrm{C}$, which may be due to the decomposition of carbonate phase present at trace level. The endothermic dissociation of carbonate is reported to occur at temperatures between 400 and $600^{\circ} \mathrm{C}$ in air and between 500 and $890^{\circ} \mathrm{C}$ in nitrogen atmosphere (Joschek et al 2000). Hence, heat treatments were planned at 300 ,

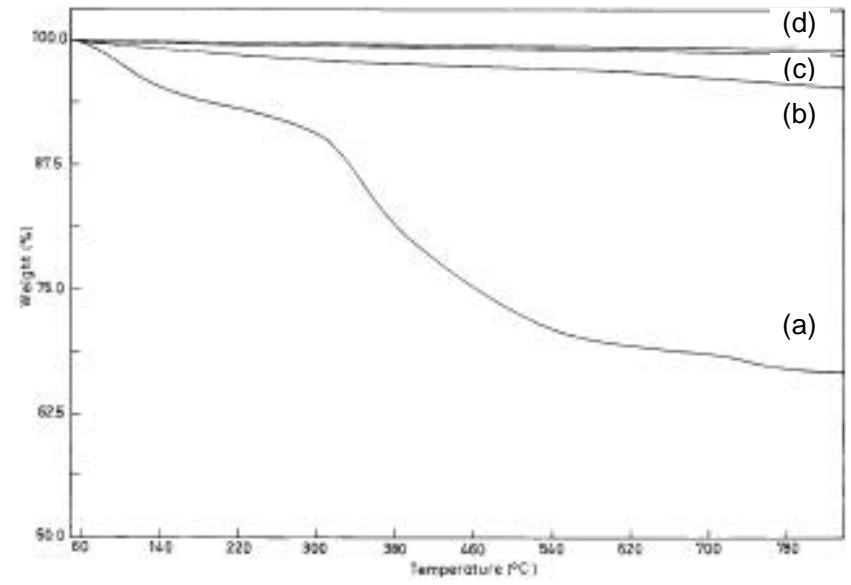

Figure 1. TG-thermogram of (a) xenogeneic raw bone and bone heated at (b) $500^{\circ} \mathrm{C}$, (c) $700^{\circ} \mathrm{C}$ and (d) $900^{\circ} \mathrm{C}$.
500,700 and $900^{\circ} \mathrm{C}$ to study the changes observed in the HA as well as the removal of the organic debris. The average amount of organic phase removed at these temperatures during heat deproteination was calculated and listed in table 1 . No organic materials were removed from the raw bone as it was not heated. In the case of bone heated at $300^{\circ} \mathrm{C}$, the average percentage of organic phase removed was found to be $82.4 \%$, whereas $100 \%$ of organic phase was removed for 500,700 and $900^{\circ} \mathrm{C}$ heated samples. These results suggested that they are free from organic debris and hence may prevent immunological response upon implantation.

The amount of collagen present in the bone samples was calculated by indirect method using hydroxyproline estimation. The percentage of collagen present in each bone sample is listed in table 1. The results suggested that there is a definite decrease in the amount of collagen with increase in the temperature. The percentage of collagen present in the raw bone was found to be $18.3 \%$ whereas it was $5 \cdot 2 \%$ for the bone heated at $300^{\circ} \mathrm{C}$, which indicated that organic matters still existed in these samples. It was found that the collagen content was zero for 500,700 and $900^{\circ} \mathrm{C}$ samples, which confirmed the complete removal of organic debris associated with the bone, leaving behind the inorganic mineral phase only. Hence, the remaining inorganic phase after heat treatment at $500^{\circ} \mathrm{C}$ may be absolutely free from antigenicity and may not cause any immunological reactions. The biocompatibility of the HA is well known (Muller-Mai et al 1995). Hence the removal of organic phases may not hinder the biocompatibility of implant materials.

The X-ray powder diffraction method is employed to assess the phase purity and the structural changes of the bone samples. Figure 2 summarizes the XRD patterns of raw bone and bone heated at different temperatures.

Table 1. Structural properties of raw and heat-treated bone samples.

\begin{tabular}{|c|c|c|c|c|c|}
\hline \multirow[b]{2}{*}{ Properties } & \multirow[b]{2}{*}{ Raw bone } & \multicolumn{4}{|c|}{ Bone heated at } \\
\hline & & $300^{\circ} \mathrm{C}$ & $500^{\circ} \mathrm{C}$ & $700^{\circ} \mathrm{C}$ & $900^{\circ} \mathrm{C}$ \\
\hline Organic phase removed (\%) & NOR* & $82 \cdot 4$ & 100 & 100 & 100 \\
\hline $\begin{array}{l}\text { Amount of organic removed } \\
\text { (mg/g of bone sample) }\end{array}$ & NOR* & 247 & 299 & 302 & 303 \\
\hline $\begin{array}{l}\text { Amount of collagen } \\
(\mathrm{mg} / \mathrm{g} \text { of bone tissue }) * *\end{array}$ & 183 & 52 & 0 & 0 & 0 \\
\hline $\begin{array}{l}\text { Carbonate content }(\%) \\
\text { by spectroscopy method }\end{array}$ & $5 \cdot 4 \pm 0 \cdot 82$ & $5 \cdot 0 \pm 0 \cdot 71$ & $4.4 \pm 0.42$ & $2 \cdot 6 \pm 0 \cdot 64$ & $2 \cdot 3 \pm 0 \cdot 16$ \\
\hline $\begin{array}{l}\text { Carbonate content (\%) } \\
\text { by CHN analyser }\end{array}$ & $5 \cdot 5 \pm 0 \cdot 64$ & $5 \cdot 2 \pm 0 \cdot 44$ & $4 \cdot 6 \pm 0 \cdot 26$ & $2 \cdot 7 \pm 0 \cdot 36$ & $2 \cdot 2 \pm 0 \cdot 28$ \\
\hline FWHM [002 peak] & $0.640 \pm 0.058$ & $0 \cdot 582 \pm 0 \cdot 042$ & $0.465 \pm 0.068$ & $0.314 \pm 0.038$ & $0 \cdot 306 \pm 0 \cdot 024$ \\
\hline FWHM [211 peak] & $1 \cdot 268 \pm 0 \cdot 094$ & $1 \cdot 210 \pm 0 \cdot 064$ & $0 \cdot 986 \pm 0 \cdot 072$ & $0 \cdot 420 \pm 0 \cdot 041$ & $0.412 \pm 0.032$ \\
\hline [002] peak location $(2 \theta)$ & $26 \cdot 10$ & $26 \cdot 14$ & $25 \cdot 92$ & $26 \cdot 02$ & $25 \cdot 94$ \\
\hline [211] peak location $(2 \theta)$ & $32 \cdot 02$ & $32 \cdot 06$ & 31.92 & $31 \cdot 82$ & 31.83 \\
\hline
\end{tabular}

*No organic phase removed since, raw bone was not heated. Data given were the average of two samples and adjusted for $\mathrm{H}_{2} \mathrm{O}$ content using a control at $50^{\circ} \mathrm{C}$. Total amount of organic matters was found to be $0 \cdot 3 \mathrm{~g} / \mathrm{g}$ of raw bone tissue.

$* *$ Calculated by hydroxyproline estimation. 
The XRD pattern of raw bone (figure 2a) showed amorphous phase as the organic materials are still within the bone mineral, whereas the bone heated at 300 and $500^{\circ} \mathrm{C}$ showed semi-crystalline phases (figures $2 \mathrm{~b}$ and $\mathrm{c}$, respectively). A slight qualitative change in the crystallinity between raw bone and bone heated at 300 and $500^{\circ} \mathrm{C}$ was

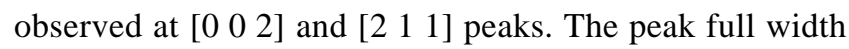
at half-maximum height (FWHM), an inverse measure of crystal size and crystallinity was not significantly different for the raw bone and bone heated at 300 and $500^{\circ} \mathrm{C}$

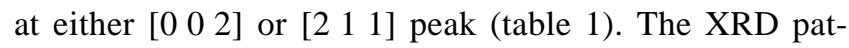
terns of bone heated at 700 and $900^{\circ} \mathrm{C}$ (figures $2 \mathrm{~d}$ and e, respectively) were identical and showed highly crystalline phases as compared to 300 and $500^{\circ} \mathrm{C}$ samples. The heat treatment at 700 and $900^{\circ} \mathrm{C}$ caused substantial changes in the Bragg diffracted peaks when compared to raw bone and bone heated at 300 and $500^{\circ} \mathrm{C}$. The background signals were also reduced in both the cases. The results showed the step-by-step transformation of the amorphous raw bone to crystalline state with the corresponding decrease of the organic phases with increasing temperature. The high temperature heat treatment reduced the FWHM of [0 002$]$ and [2 111$]$ peaks to 51 and $69 \%$, respectively, of the bone heated at $700^{\circ} \mathrm{C}$ and 52 and $68 \%$, respectively for the bone heated at $900^{\circ} \mathrm{C}$ when compared to the raw bone. This is a quantitative evidence that the peaks of bone heated at 700 and $900^{\circ} \mathrm{C}$ are more distinct and sharper, which indicated that the thermal process at high temperature brings about substantial improvement in the crystallinity and crystal size. The Bragg peaks at $\sim 26,28,29,30-35,39,46,49$, and $50^{\circ}$ (20) observed for bone heated at 500,700 and $900^{\circ} \mathrm{C}$

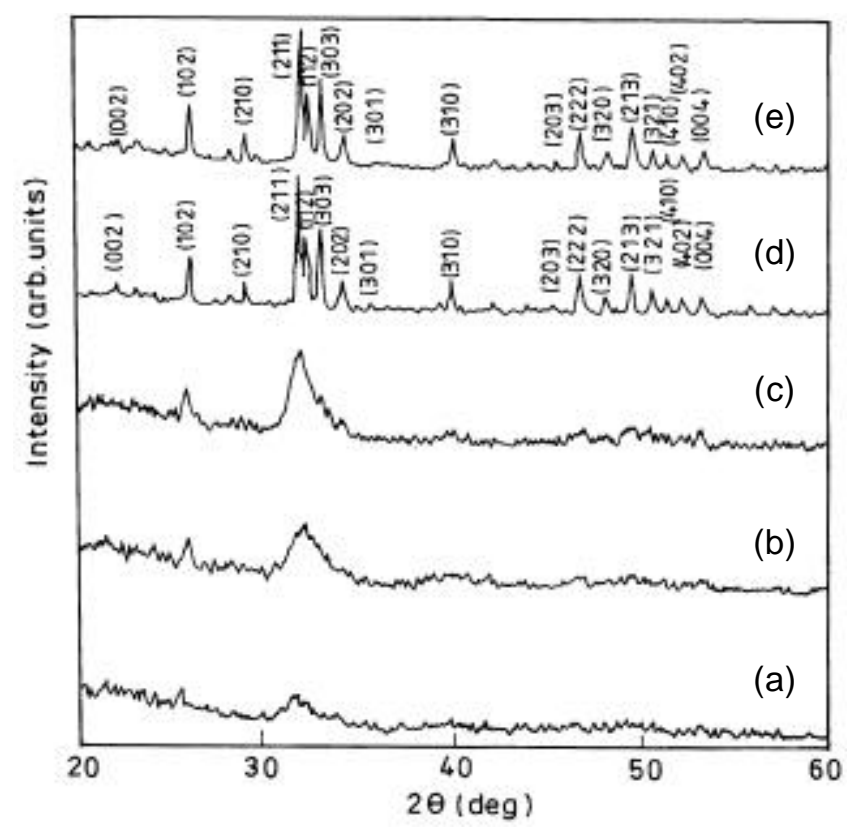

Figure 2. XRD patterns of (a) raw bone and bone heated at (b) $300^{\circ} \mathrm{C}$, (c) $500^{\circ} \mathrm{C}$, (d) $700^{\circ} \mathrm{C}$ and (e) $900^{\circ} \mathrm{C}$. corresponded to the characteristic peaks of HA (JCPDS 9-432). However, there were no sharp and distinct peaks detected for the bone heated at $500^{\circ} \mathrm{C}$ owing to low temperature process. The peaks observed for 700 and $900^{\circ} \mathrm{C}$ exhibited that the heating at high temperatures $(700$ $900^{\circ} \mathrm{C}$ ) brought about substantial improvements in the crystallinity and hence an increase in crystal size. The results suggested that there were no secondary phases except for HA phase observed for heat treated bone samples particularly at 500,700 and $900^{\circ} \mathrm{C}$, which confirmed their phase purity. The heat treated bone at $500^{\circ} \mathrm{C}$ has the properties similar to carbonated hydroxyapatite with low crystallinity as indicated by FTIR analysis, whereas 700 and $900^{\circ} \mathrm{C}$ heated bone samples have the same properties with high crystallinity.

The well resolved XRD peaks of bone heated at 700 and $900^{\circ} \mathrm{C}$ can be easily indexed on the basis of hexagonal crystal system of space group $P 6_{3} / m$ with respect to JCPDS file no. 9-432 (figures $2 \mathrm{~d}$ and e, respectively). The lattice cell parameters were calculated by refining the XRD data by standard least square method using the 'CELN' programme. The calculated lattice cell parameters of heat treated bone samples corresponded more to be carbonated hydroxyapatite (Sampath Kumar et al 2000) as listed in table 2. These results suggested that the deproteination of xenogeneic bone obtained by this simple method gave carbonated HA with variable crystallinity.

The FTIR spectra of raw bone and heat treated bones are illustrated in figure 3. It was found from the results that IR spectrum of all the samples showed a major peak at $3500 \mathrm{~cm}^{-1}$ due to the presence of the hydroxyl group. More absorption peaks were noted for the raw bone and bone heated at $300^{\circ} \mathrm{C}$ : a strong $\mathrm{N}-\mathrm{H}$ stretching band around $2900 \mathrm{~cm}^{-1}$ and amide bands at 660 and $1550 \mathrm{~cm}^{-1}$. These two peaks are pertaining to macromolecules of protein associated with xenogeneic bone. These two peaks disappeared for the bone heated at 500,700 and $900^{\circ} \mathrm{C}$, which suggested that they are free from organic impurities. There were no significant differences observed in the FTIR spectra of 500, 700 and $900^{\circ} \mathrm{C}$ which indicated that the heat treatment had not stimulated any secondary phase transformation. The IR spectrum of bone heated

Table 2. List of lattice cell parameters of heat-treated bone samples calculated from the XRD analysis.

\begin{tabular}{lccc}
\hline & \multicolumn{2}{c}{ Lattice constants } & \\
\cline { 2 - 3 } Samples & $a_{0}=b_{0}(\AA)$ & $c_{0}(\AA)$ & $c_{0} / a_{0}(\AA)$ \\
\hline Bone heated at $500^{\circ} \mathrm{C}$ & 9.435 & 6.902 & 0.732 \\
Bone heated at $700^{\circ} \mathrm{C}$ & 9.429 & 6.889 & $0 \cdot 731$ \\
Bone heated at $900^{\circ} \mathrm{C}$ & 9.426 & 6.894 & 0.731 \\
CHA $^{*}$ & 9.425 & 6.902 & 0.732 \\
HA (JCPDS 9-432) & 9.418 & 6.884 & 0.730 \\
\hline
\end{tabular}

*Carbonated HA (Sampath Kumar et al 2000). 
at 500,700 and $900^{\circ} \mathrm{C}$ exhibited only the characteristic absorption peaks of HA (Joschek et al 2000; Matsumoto et al 2002). The FTIR spectra indicated the presence of $\mathrm{PO}_{4}^{3-}$ and $\mathrm{OH}^{-}$ions in all the samples. The 1043 and $970 \mathrm{~cm}^{-1}$ bands were assigned to the stretching vibrations of $\mathrm{PO}_{4}^{3-}$ ions and 605 and $569 \mathrm{~cm}^{-1}$ bands were assigned to the deformation vibrations of $\mathrm{PO}_{4}^{3-}$ ions (Featherstone et al 1984). The bands at $3546 \mathrm{~cm}^{-1}$ and $640 \mathrm{~cm}^{-1}$, were due to the vibration motion of the $\mathrm{OH}^{-}$ions (Zhang and Gonsalves 1997).

The FTIR spectra also indicated the absorption peak of carbonate ions around $1450 \mathrm{~cm}^{-1}$ (Jensen et al 1996) in all the samples. The heat treatment had little effect on the carbonate content of the bone samples. A small

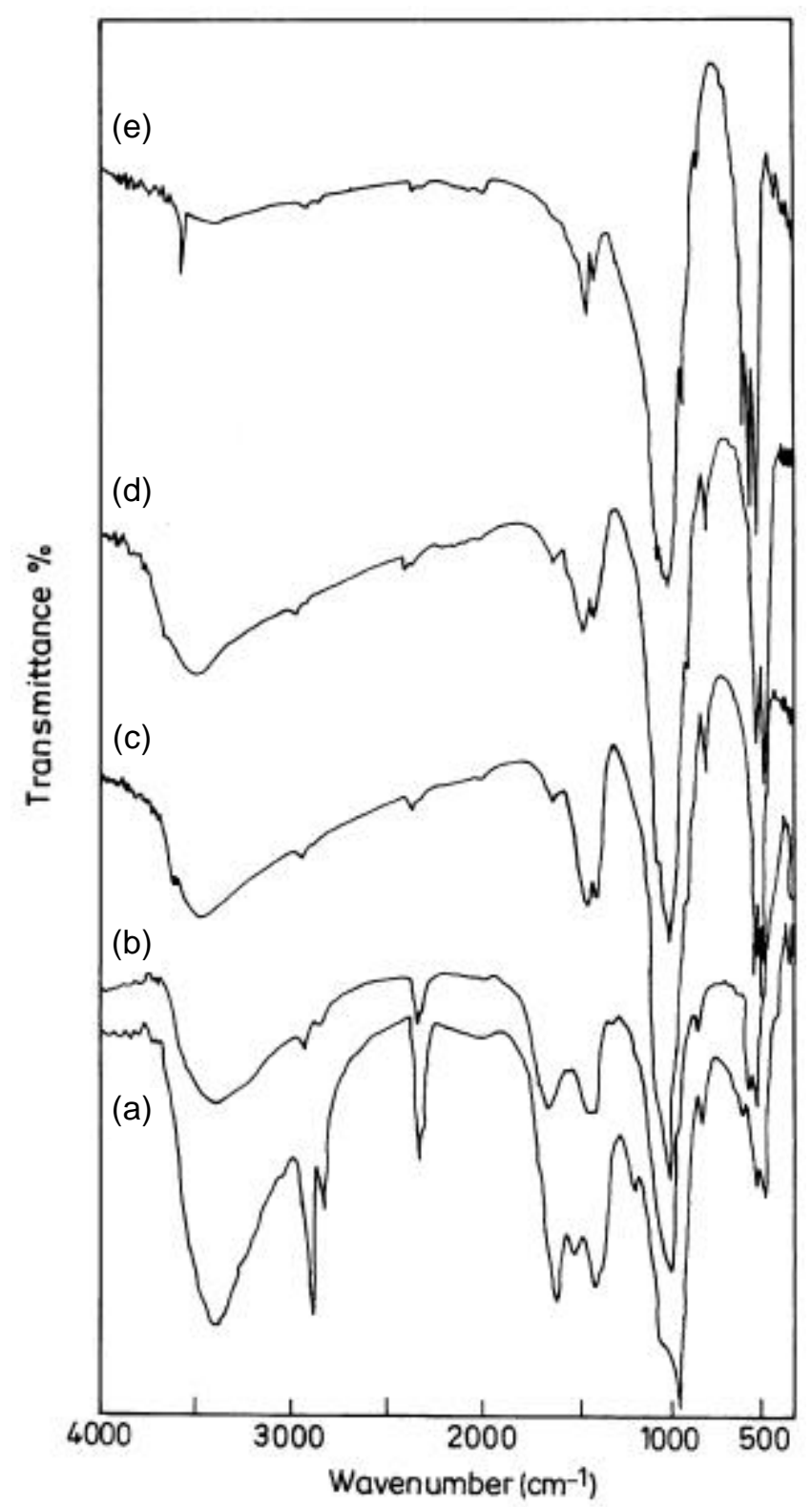

Figure 3. FTIR spectra of (a) raw bone and bone heated at (b) $300^{\circ} \mathrm{C}$, (c) $500^{\circ} \mathrm{C}$, (d) $700^{\circ} \mathrm{C}$ and (e) $900^{\circ} \mathrm{C}$. reduction in the amount of carbonate was observed for the bone heated at 300 and $500^{\circ} \mathrm{C}$ as compared to raw bone (table 1), which may be due to the presence of organic impurities associated with the bone. As expected, the bone heated at 700 and $900^{\circ} \mathrm{C}$ had much reduced carbonate content due to high temperature process. These results were also confirmed by calculating the amount of carbonate content using $\mathrm{CHN}$ analyser as given in table 1. These data suggested that the carbonate contents calculated by both the spectroscopic method and CHN elemental analyser corroborated well. The presence of carbonate in the samples suggested that the heat-deproteinated xenogeneic bone was a hydroxyl carbonate apatite. The bone mineral contains $4-8 \mathrm{wt}$.\% of carbonate in human body and its presence in the apatite phase is advantageous as it increases the mechanical strength and bioactivity (Waish et al 1994; Mery et al 1998). The carbonate content in the bone heated at $500^{\circ} \mathrm{C}$ falls within the range of carbonate present in the human bone minerals as indicated in table 1. These findings imply that no secondary phase transformation occurred during heat treatment and the deproteinated xenogeneic bone is of hydroxyl carbonate apatite, which is beneficial for biomedical purposes due to its similarity with the bone apatite.

Study on thermal behaviour of HA is of great importance, when used as coatings on metallic implants (Chen et al 1997). The TG-thermograms, in terms of weight loss, of bone heated at different temperatures are shown in figure 1. The TG-trace of bone heated at 500, 700 and $900^{\circ} \mathrm{C}$ do not show the weight loss pertaining to the decomposition/evaporation of protein macromolecules, which suggested that they are absolutely free from organic debris as confirmed by FTIR qualitatively and by collagen estimation quantitatively. The observed total weight loss of about $5 \%$ for bone heated at $500^{\circ} \mathrm{C}$ can be due to dehydroxylation. The presence of carbonate at this temperature $\left(500^{\circ} \mathrm{C}\right)$ was confirmed by FTIR and $\mathrm{CHN}$ analyses. There was no significant change observed in the thermograms of bone heated at 700 and $900^{\circ} \mathrm{C}$. However, the observed small weight loss $(<2 \%)$ can be due to the release of hydroxyl ions according to

$$
\mathrm{Ca}_{10}\left(\mathrm{PO}_{4}\right)_{6}(\mathrm{OH})_{2} \rightarrow \mathrm{Ca}_{10}\left(\mathrm{PO}_{4}\right)_{6}(\mathrm{OH})_{2-2 x} \mathrm{O}_{x}+\mathrm{H}_{2} \mathrm{O} \text {. (3) }
$$

Further, due to very less amount of carbonate as indicated by $\mathrm{CHN}$ analyser, the TG-analysis do not show significant weight loss for dissociation of carbonate ions at these temperatures.

Figure 4 shows SEM observations of raw bovine bone and $500^{\circ} \mathrm{C}$ heated bone. The microstructure of raw bone (before deproteination) was highly dense due to the presence of organic substances impregnated with inorganic minerals associated with the xenogeneic bone (figure $4 \mathrm{a}$ ). Figure $4 \mathrm{~b}$ revealed that the heat treated bone at $500^{\circ} \mathrm{C}$ contains numerous pores. It may be suggested that the porous architecture had been created by the removal of 

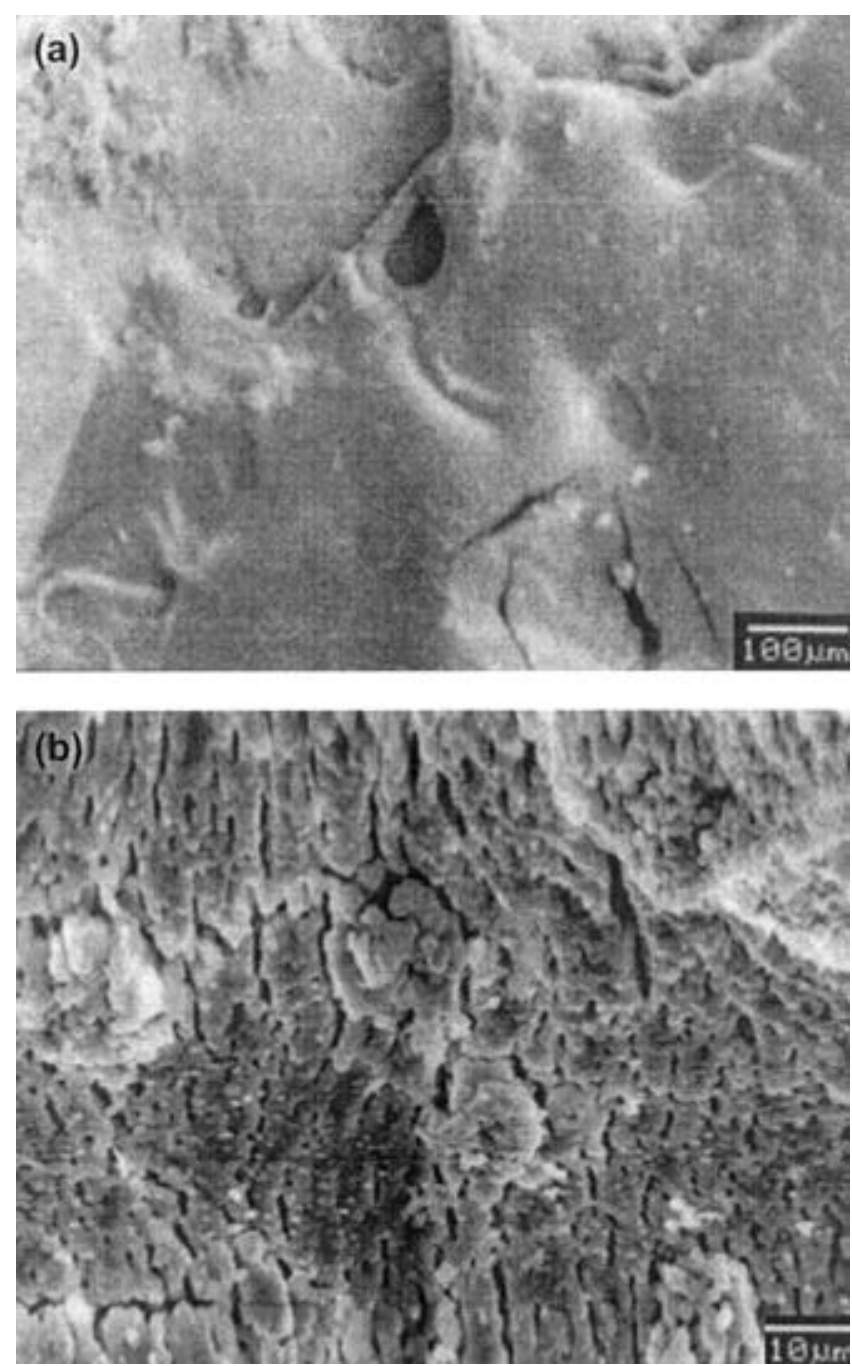

Figure 4. SEM photographs of (a) raw bone and (b) bone heated at $500^{\circ} \mathrm{C}$.

organic phases by heat treatment. The obtained porous architecture resembles that of human cancellous bone and hence it may be expected that the porous feature of hydroxyl carbonate apatite would be beneficial for the bone in-growth upon implantation.

\section{Conclusions}

The present study showed the possibility of preparing protein-free inorganic minerals of xenogeneic bone by a simple thermal process. The heat deproteinated xenogeneic bone corresponded to hydroxyl carbonate apatite phase. The phase purity was confirmed by XRD and FTIR analyses. The effect of heat treatment in addition promoted the crystallinity of the bone samples. The FTIR revealed that the organic macromolecules were eliminated at $500^{\circ} \mathrm{C}$. So, we propose that the bone heated at a low temperature of $500^{\circ} \mathrm{C}$ can be used as a potential bone filling material since it has similar properties of carbonated crystalline HA. Hence this study paved the way to make value added healthcare material like HA from the slaughterhouse waste at economical limits.

\section{Acknowledgements}

One of the authors (RM) would like to acknowledge the Council of Scientific and Industrial Research, New Delhi, for the fellowship grant. The initial stage of work was supported through Career Award project, COSIST and SAP programs of the University Grants Commission, New Delhi.

\section{References}

Armstrong W E and Singer L 1965 Clin. Orthop. 38179

Arrigton E D, Smith W E, Chambers H G, Bucknell A L and Davidino N A 1996 Clin. Orthop. Rel. Res. 329300

Chen J, Tong W, Yang C, Feng J and Zhang X 1997 J. Biomed. Mater. Res. 3415

De Groot K 1980 Biomaterials 147

Featherstone J D, Pearson S and Le Geros R Z 1984 Caries Res. 1863

Gong J K, Arnold J S and Cohn S H 1964 Anat. Rec. 149325

Jarcho M 1981 Clin. Orthop. Rel. Res. 157259

JCPDS File No. 9-432, 1980 International Centre for Diffraction Data, Pennsylvania, USA

Jensen S S, Aaboe M and Piahold E M 1996 Int. J. Oral Maxillofac. Imp. 1155

Joschek S, Nies B, Krotz R and Gopferich A 2000 Biomaterials 211645

Katthagen B D 1986 Bone regeneration with bone substitutes: An animal study (Berlin: Springer)

Lin F H, Liao C J, Chen K S and Sun J S 1999 Biomaterials 20 475

Locardi B, Pazzaglia U E, Gabbi C and Profilo B 1993 Biomaterials 14437

Matsumoto T, Okazaki M, Inoue M, Hamada Y, Taira M and Takahashi J 2002 Biomaterials 232241

Merry J C, Gibson I R, Best S M and Bonfield W $1998 \mathrm{~J}$. Mater. Sci.: Mater. Med. 9779

Muller-Mai C M, Stupp S I, Voigt C and Gross U 1995 J. Biomed. Mater. Res. 299

Neuman R E and Logan M 1950 J. Biol. Chem. 184299

Paul W and Sharma C P 1997 J. Mater. Sci. Lett. 162050

Raspanti M, Guizzardi S, De Pasquale V, Martini D and Ruggeri A 1994 Biomaterials 15433

Sampath Kumar T S, Manjubala I and Gunasekaran J 2000 Biomaterials 211623

Stevension S 1999 Orthop. Clin. North Am. 30543

Tancred D C, Carr A J and McCormack B A O 1998 J. Mater. Sci.: Mater. Med. 9819

Urist M R, O'Connor B T and Burwell R G 1994 Bone grafts, derivatives and substitutes (London: Butterworth-Heinemann)

Walsh W R, Labrador D P, Kim H D and Guzelsu N 1994 Ann. Biomed. Engg. 22404

Zhang S and Gonsalves K E 1997 J. Mater. Sci.: Mater. Med. 8 25 